\title{
Bem-vindos ao cemitério Vera Cruz de Passo Fundo, RS
}

\author{
Welcome to Vera Cruz cemetery in Passo Fundo, RS
}

MIRANDA, Fernando e ZANOTTO, Gizele (orgs.). A Morte não é o fim: Culturas e identidades no cemitério Vera Cruz. Passo Fundo: Projeto Passo Fundo, 2018. 292p.

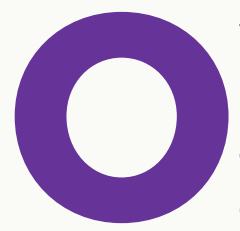

título do livro organizado pelos historiadores Fernando Miranda e Gizele Zanotto bem poderia abordar um tema de ordem soteriológica, como o do cemitério, pelo viés do campo das religiões. No entanto, a coletânea de textos do livro A morte não é o fim. Culturas e identidades no cemitério Vera Cruz leva o leitor a adentrar esse espaço cemiterial, localizado na cidade de Passo Fundo, no Rio Grande do Sul. Sua leitura nos guia à reflexão sobre possibilidades de pesquisa na própria necrópole, bem como em muitas outras no Brasil.

Logo na apresentação da obra, os organizadores convidam o leitor para que "junte-se ao Projeto Museu a Céu Aberto e muna-se de um Guia de Visitação", posto que o livro lhe permite apreciar "um dos maiores patrimônios histórico/ cultural/artístico da cidade!" (p. 14). Ao longo de suas 292 páginas, esse convite conduz o leitor a visitar o cemitério Vera Cruz a partir de três dimensões de leitura. A primeira se situa sob o olhar educativo, histórico e patrimonial que este cemitério e tantos outros podem fornecer, uma vez que muitos têm sido os estudos a contribuir para a percepção dos cemitérios como importantes patrimônios culturais. A segunda se volta para as identidades, crenças e símbolos presentes nos vestígios desta

* Mestre em História Social pela Universidade Federal de Uberlândia (UFU/MG). Pastor pelo Seminário Luterano Concórdia, São Leopoldo, RS. http://lattes.cnpq.br/0642108932487415 
necrópole. Por fim, fechando a terceira propõe textos que apresentam uma relação de 100 túmulos contendo epitáfios que permitem ao leitor uma visita guiada pelos próprios "moradores desse espaço" (p. 167).

Ao adentrar o cemitério Vera Cruz pelas páginas desta obra, o leitor se dá conta de que os cemitérios são importantes contribuições para o entendimento da sociedade na qual está inserido, independentemente do seu processo de criação, da sua localidade ou do seu tempo de existência. Aspecto que ocorre independente da perspectiva do leitor: seja ele um estudioso dos espaços cemiteriais ou apenas alguém que tem simpatia pelo assunto. Os rastros deixados pela vivência do luto e das diferentes práticas e rituais realizadas no cemitério são inegáveis fontes de pesquisa para muitos campos de estudo e áreas do conhecimento, passando pela história, arte, filosofia, arquitetura, política, antropologia e tantas outras.

Como locus por meio do qual pode se identificar representações sociais, eles ajudam na compreensão das vivências e atribuições de sentido dados à vida (Jodelet, 2001, p. 21), em decorrência da relação íntima e incontestável entre os túmulos e seus signos. Os textos de A morte não é o fim atestam essa relação dando a devida importância às representações culturais da morte, tendo em vista que as inscrições funerárias "estão entre os primeiros rastros de signos escritos confirmando-nos, igualmente, quão inseparáveis são memória, escrita e morte" (Gagnebin, 2006, p. 45). Não por acaso, os textos que levam o leitor a visitar e a fazer a leitura da necrópole aqui evidenciada têm como fonte de pesquisa o espaço cemiterial com sua escrita feita de "arquivos de pedra" (Le Goff, 2003, p. 428).

Na primeira parte do livro, intitulada "Vera Cruz sob olhar educativo, histórico e patrimonial", o leitor percorre a visita guiado por temas como educação patrimonial, história política, formação étnica de Passo Fundo, modernização urbana, organização espacial do cemitério e história dos primeiros sepultamentos e fundação do cemitério Vera Cruz. A historiadora Jenny González Munoz destaca, em "Educación para el patrimônio: el cementerio Vera Cruz como espacio de arte y memoria", destaca que a visita ao cemitério serve de ferramenta para educação patrimonial (p. 22), mas é apenas uma parte do processo pedagógico (p. 31), que jamais deve ser confundida com educação patrimonial (p. 31), posto que essa última deve estar acompanhada de discussões teóricas e conceituais sobre o tema e inserida em uma investigação educativa. Caminhando nesse sentido, o trabalho dos historiadores Djiovan Vinícius Carvalho e Alex Antônio Vanin, "A história por entre as sepulturas: possibilidades de abordagens e ensino de história no cemitério Vera Cruz", apresenta um projeto de como uma visita guiada em um cemitério pode servir de leitura e compreensão da história local e fomentar o desejo pela preservação patrimonial, ao argumentar que os arquivos de pedra não somente podem, como devem ser conservados.

Ainda na primeira parte da coletânea, o cemitério Vera Cruz tem a sua história contada pelos trabalhos dos historiadores Eduardo Roberto Jordão Knack, em "Cemitérios e modernização urbana", e Áxsel Batistella de Oliveira, Caroline da Silva e Waleska Gaspar, em "Regulando as mortes: os cemitérios e os sepultamentos nos códigos de postura municipais de Passo Fundo (1884-1950)". O primeiro texto problematiza a fundação do cemitério Vera Cruz e sua relação com a modernização urbana da cidade de Passo Fundo. Evidenciam como, 
no projeto de cidade, o mesmo espaço imaginado para se localizar distante da área urbana foi gradativamente engolido pelo crescimento urbano. O segundo texto, ao mesmo tempo em que apresenta um breve histórico da fundação do cemitério, conduz o leitor a conhecer os regulamentos de enterramentos do final do século XIX e, especialmente, da primeira metade do século XX, no período pós-fundação do cemitério, em 1902.

Por fim, a primeira parte dessa visita guiada volta seu olhar para a arquitetura, por meio dos trabalhos de Mirian Casarek, Greice Barufaldi Rampanelli, Bruna de Marchi, Cristina Pesente e Maria Anita da Silva, no capítulo "Espaço de transformação - organização espacial do cemitério Vera Cruz". Nesse olhar interdisciplinar, a visita volta-se para a organização física do espaço, de como ele foi pensado e tratado por uma leitura da história do urbanismo, concluindo que esse cemitério poderia ser visto como um organismo vivo (p. 71) e, como tal, deveria receber maior atenção do poder público, denunciando "a falta de planejamento e infraestrutura" (p. 75) por parte dos gestores institucionais.

A segunda seção da coletânea é dividida em cinco capítulos e ganha o subtítulo de "Símbolos, crenças e identidades: vestígios de um espaço cemiterial", direcionando o olhar dos visitantes não apenas para a formação e história do espaço em si, mas sobretudo para o que ali foi erguido, seja pelas lápides e mausoléus ou pelas inscrições dos epitáfios. O capítulo que abre a seção, "Representações simbólicas e alegóricas no cemitério Vera Cruz", da historiadora Jacqueline Ahlert, traz uma análise de 44 imagens (p. 104-108) de sepulturas, tendo como base a tipologia cristã, alegórica e celebrativa. Nele, discute como essas imagens e seus símbolos trabalham com a ausência e, nesse sentido, convida o leitor a "atentar as imagens no espaço cemiterial e delas absorver os possíveis significados" (p. 95). Dando continuidade à segunda parte da obra, os epitáfios e seus significados são explorados em "A construção da identidade dos sujeitos através dos epitáfios: uma análise do cemitério Vera Cruz", de autoria das professoras do curso de Letras da Universidade de Passo Fundo (UPF), Elisane Regina Cayser e Luciana Maria Crestani. Embasando-se na retórica aristotélica, a partir de conceitos como ethos, pathos e logos, as autoras analisam alguns epitáfios, dando um panorama do que os visitantes podem encontrar e ler nas lápides da necrópole. Com ênfase no ethos "relacionado a uma maneira de dizer que remete a uma maneira de ser atrelada a uma cena enunciativa que valida o que é dito e como é dito" (p. 113), as autoras dividem suas análises pelo ethos religioso, profissional, profético, do arrependimento, e do inconformismo.

No capítulo "Eis o meu campo santo...: lugares de devoção no cemitério Vera Cruz", a historiadora Gizele Zanotto convida o leitor/visitante a conhecer lugares de fé na cidade dos mortos, explicando como a geografia social presente na cidade também se reflete na morada dos mortos (p. 127). Zanotto apresenta os lugares de fé nos cemitérios, reconhecidos ou não pelas autoridades eclesiásticas. No caso do cemitério Vera Cruz, o local de devoção popular acontece junto ao jazigo de Maria Elisabeth de Oliveira, considerada santa pelos seus devotos e operadora de milagres.

No trabalho que fecha a seção, "Aqui jaz: local de passagem, esquecimento ou exílio?", a historiadora Francielle Moreira Cassol problematiza o cemitério como espaço também do esquecimento, por meio da comparação entre a urna 78, o jazigo de Maria Elisabeth Oliveira 
(santa popular) e o mausoléu/monumento aos expedicionários. O texto conduz o visitante a voltar seu olhar para os esquecidos da necrópole e a refletir sobre aqueles que fazem parte do espaço cemiterial que hoje "são figuras do esquecimento, pois seu significado esvaiu-se no transcorrer no tempo ou na memória social" (p. 149).

Por fim, no último trabalho desta segunda parte do livro e do roteiro de visitação, o leitor visitante é conduzido ao mausoléu dos expedicionários pela mão dos historiadores Alessandro Batistella e Alex Antônio Vanin, em "O mausoléu do cemitério Vera Cruz: patrimônio histórico de Passo Fundo". Nesse trabalho, é relatada a história curiosa de um mausoléu construído para o capitão Jovino da Silva Freitas, cuja família cede o mesmo espaço para receber os restos mortais de onze militares mortos na Revolta Constitucionalista de 1932, transferindo o corpo do capitão para uma sepultura vizinha. O mausoléu destaca-se no cemitério Vera Cruz por sua arquitetura e atenção que recebeu do Exército para sua restauração e posterior tombamento como patrimônio histórico de Passo Fundo.

$\mathrm{Na}$ terceira parte da visita guiada, o visitante tem a oportunidade de conhecer a relação de 100 túmulos, por meio da leitura do trabalho dos historiadores Fernando Miranda, Djiovan Vinícius Carvalho e Alex Antônio Vanin, "Ad Sumus: a cidade dos mortos dentro da cidade dos vivos". Nessa relação feita com base na pesquisa em documentos publicados em necrológios, registros de óbitos, casamentos realizados pela Igreja Católica, além de periódicos, impressos e obras sobre a história da cidade, o leitor é conduzido pelos próprios "moradores" do cemitério Vera Cruz a conhecer não apenas as suas próprias histórias biográficas, mas a história da cidade de Passo Fundo.

Fechando o livro, a seção intitulada "Cultura, memória e história em foco - Cemitério Vera Cruz: museu a céu aberto" é escrita por um grupo de pesquisadores, membros da comissão do Projeto Museu a Céu Aberto, que apresentam um panorama histórico do Cemitério Vera Cruz, bem como o processo e criação do próprio projeto. Segundo seus autores, Djiovan Carvalho, Fernando Miranda, Gizele Zanotto, Greice Baruffo Rampanelli, Mirian Carasek, Josiane Pasqualotto, Pedro Lago Battezinio, o projeto "visa a preservação e a valorização de um ambiente específico: o cemitério Vera Cruz em Passo Fundo, a fim de demonstrar a força deste vínculo dos vivos com os mortos, numa associação simbólica das pessoas com o lugar" (p. 278). Neste último texto, o convite ao leitor/visitante vai além de apenas percorrer fisicamente o cemitério, levando-o a conhecer e compreender melhor a investigação desenvolvida pelo Instituto Histórico de Passo Fundo, que tem apoio do Arquivo Histórico Regional.

Após esse tour pelo cemitério, através das páginas de A morte não é o fim: Culturas e identidades no cemitério Vera Cruz, o leitor visitante pode perceber que está conhecendo esse campo de pesquisa e se sentir incentivado a se aprofundar mais sobre esse rico e vivo tema da historiografia. Para aqueles que já estudam a temática há algum tempo, as páginas dessa obra confirmam que, apesar de retratar um cemitério específico, a publicação estimula o despertar para as inúmeras possibilidades de conhecer-se a história não apenas dessa localidade, mas das necrópoles em geral, como instrumento e porta de entrada para investigações mais amplas, com perspectivas transdisciplinares.

Assim como não existe somente a história regional, igualmente não existe uma história 
sem ser regional, conforme nos diz Durval Muniz de Albuquerque Júnior ao afirmar que: "o historiador regional tem que deixar de ser historiador regional... o historiador do regional deve, acima de tudo, evitar aderir a qualquer discurso regionalista" (Albuquerque Jr., 2008, p. 65). A partir dessa constatação, percebemos que a história do cemitério Vera Cruz de Passo Fundo não está dissociada de um contexto bem mais amplo. Nesse sentido, pela sua vasta bibliografia apresentada nos textos da coletânea, A morte não é o fim: Culturas e identidades no cemitério Vera Cruz, confirma o quanto as pesquisas sobre esse espaço estão ligadas ao um contexto maior e ainda permitem a possibilidade de se desdobrarem em mais pesquisas sobre outros espaços cemiteriais, sejam de pequenas e médias localidades do interior do Brasil, que precisam ser visitadas, ou mesmo das metrópoles mais desenvolvidas.

\section{Referências Bibliográficas}

ALBUQUERQUE JÚNIOR, Durval Muniz de. O objeto em fuga: algumas reflexões em torno do conceito de região. Fronteiras. Dourados, v. 10, n. 17, p. 55-67, jan./jun. 2008.

GAGNEBIN, Jeanne M. Lembrar, escrever, esquecer. São Paulo: Editora 34, 2006. 223p.

JODELET, Denise (Org.). As representações sociais. Rio de Janeiro: EDUERJ, 2001. 416p.

LE GOFF, Jaques. História e memória. Campinas: Editora Unicamp, 2003. 504p.

MIRANDA, Fernando e ZANOTTO, Gizele (Orgs.). A Morte não é o fim: Culturas e identidades no cemitério Vera Cruz. Passo Fundo: Projeto Passo Fundo, 2018. 292p.

Recebida em: 30 de novembro de 2019

Aprovada em: 11 de dezembro de 2019 